\title{
Assessing Arabic language learning for deaf student: A Study of using mobile immersion in Saudi Arabia
}

\author{
Jawaher Jamaan, Zainatul Shima Abdullah \\ Dept of Information and Communication Technology, International Islamic University Malaysia, Kuala Lumpur, Malaysia \\ bjawaher11@gmail.com \\ Dept of Information and Communication Technology, International Islamic University Malaysia, Kuala Lumpur, Malaysia \\ shima@iium.edu.my
}

\begin{abstract}
This research is a study on improving information facilitated by common GPS based mobile application for navigation especially by the blind users. For a blind person, the main source of information is words and how to improve the effectiveness of the explanation using mobile application for them is tested in this research. The long term goal of technology is to create a movable, self-contained system that allows visually impaired people to navigate through unfamiliar environments without the assistance of guides The experiment for the research took place at MFB (Malaysian Foundation for the Blind) using existing GPS based mobile applications and the results were used to prove the hypothesis that the blind are at a considerable downside because of the absence of information and providing a detailed description of the environment could be used in the GPS navigation applications for the blind pedestrians to help them navigate independently and it would enable them to take up GPS for independent navigation in unknown environment. The information derived from the research could further help in creating and improving the semantics of the GPS based navigation technology for the blind pedestrians in an unknown environment.
\end{abstract}

Keywords-M-learning; Deaf Student; Saudi Arabia

\section{INTRODUCTION}

Despite the importance of writing, the teaching of reading is usually given more attention than the teaching of writing. Nonetheless, there are studies investigating on the quality of writing carried out on deaf students [7, $20,21,22]$. These studies indicate that the texts written by deaf students are usually understandable, but described as having a lack of organization and supporting details, intermittent, and immature. It is likely that these qualities are because deaf students are not in complete control as the language and vocabulary is limited compared to their hearing peers.

There are many Arab studies that recommend the use of methods, techniques, and tools that contribute towards the effectiveness of teaching the Arabic language that commensurate with the circumstances and the nature of the disability of these students. This includes the study of Mahmoud [18], which demonstrated the effectiveness of three strategies for active learning in the development of written expression skills, namely: brainstorming, problem solving, and collaborative learning. The study of Anzi [8] concluded that the use of cooperative learning in the teaching of
Arabic grammar has a positive impact on the development of the academic achievement among students with disabilities acoustically in the first grade of secondary school in Riyadh. The study of Salama [25] demonstrated the effectiveness of a program based on educational situations in the job skills of reading and writing to students with disabilities in the acoustically preparatory stage of development. The study of Sayed [26] found that the use of some online tools has a significant impact on the development of achievement and literacy among deaf students.

In our society, the deaf forms a unique group of individuals with their own particular language and lifestyle. Individuals within this group show some special functions, which make them exclusive from ordinary people. The education of deaf students is a growing topic within the area of remedial education. The field of deaf studies is ordinarily characterized as the investigation of their dialect, history, writing, group and culture of individuals with hearing problems as analyzed through the contemplations of sociology and anthropology. Enhancing the literacy of deaf individuals lowers their 
reliance on others for the understanding of written texts [1]. It is without a doubt advantageous to complete a bit of exploration on this area.

The deaf student faces a broad scope of social and communication challenges. In spite of the importance of literacy in the present day and social life, the rate of literacy remains very low. The deaf depend entirely on sign language using their hands, body movements, and facial expressions to communicate their ideas to others. There is a challenge in the education of deaf student due to the lack of using technology for educational purposes. A study by Al Mulhim [6] shows that there are three reasons that prevent teachers from utilizing e-learning frequently and appropriately for their teaching, namely the lack of access to technology, the lack of effective training, and the lack of time. The focus on technological development in education for the deaf is a positive aspect to expand this field in learning and the development of knowledge [2, 27]. Furthermore, Lissi et al. [17] stated that there is growing evidence that demonstrates a connection between technologies and the educational level of deaf students.

Most strategies and methods mentioned by teachers was about cooperative learning strategies, active learning, educational games, mind map, problem solving, dialogue and debate, criticism and opinion, and sometimes individual learning. The selection of strategy relies on the needs of the students, which vary according to the severity of their disability that may require the use of more than one way of communication and teaching strategy per learner. Some of the Arabic language teachers resort to some special teaching practices which is considered useful in facilitating deaf students to absorb obscure the meanings by deaf students, Such as comparisons, simplifying the meaning to the students, the use of representation to explain the vocabulary, the segmentation of information into parts making it even easier for students, in addition to linking it with reality [4].

In Saudi Arabia, deaf students suffer from an inability to complete their higher education. The reason behind this is that deaf students have limited vocabulary and lack writing skills. Another issue in the field of deaf education is that there is less attention directed to the use and development of technology for deaf educational purposes. Therefore, the interaction of deaf students with the surrounding community is diminished, thus depriving them from practicing their reading, writing and communication skills. The focus on technological development in education for the deaf is a positive aspect in the expansion of the field of learning and the development of knowledge as acknowledged by Berndsen and Luckner [11] and Soudi [17]. This paper generally explains the educational technology policy and practice with realistic examples on how to use Apple technology by teachers and students to make a difference in the teaching and learning of students with disabilities. It also shows how the Universal Design for Apple products provides the support and motivation for students with disabilities to learn and study at school and at home. Students' and teachers' use of devices such as iPod, iPhone, and iTunes makes them realize that these devices and programs can help to focus attention on special students with disabilities, making content available, and more pronounced. It reduces the difficulties in communication resulting in the classroom, and provides proper homework.

\section{LITERATURE REVIEW}

The act of writing is a cognitive process that includes the understanding of ideas, expressive language, and mechanical skills. Writing is not only an aptitude that just develops in the elementary school years; however, to some degree it begins in the early phase of the lifetime [12]. According to [13], writing evolved from the small words that children learn and the language they hear, as well as the development of the understanding that the spoken word is not the only method for self-expression or representation of reality. Based on Gunning's [13] thoughts, written work develops from the language that children hear and use. It makes sense that people who have limited access to language can therefore have problems in the development of written language because "written language, in this example, discusses exactly to the skill to translate oral language, as example English, to a written form" [13].

Deaf children experience differences in access to sounds, which can be affected by many different factors. The limited access to the sound usually affects access to spoken language to a certain extent. If the access to spoken language were weak, the development of the written language would be affected. History has proven that deaf students have difficulties with written language, as their development of writing skills is slower than that of their normal peers. A study by Rais and Manee [24] showed that deaf students have poor writing expression skills compared to normal students. The level of written expression of deaf students is less than the level of written expression for normal students in the same grade.

Keating and Mirus [16] suggested that, "often the introduction of new technologies does not mean the total abandonment of other tools, but entails a process of incorporation, involving and influencing collaborative and complex forms of human achievement embedded within dynamic and changing cultural systems" (p. 712). A study by Power et al. [23] investigated deaf Germans' use of technology and found that $96 \%$ of their survey respondents had access to a mobile phone and used text messaging. Most respondents reported that they used their mobile to send an SMS message every day. 
A study by Al-Khalifa [5] proposed a system that provides services to help the deaf in the Arab world and has excelled, as it is a system that does not require a connection to the Web or an Internet server. [5] said that since all users are deaf they would know how to install it on their devices, such as PDA. Moreover, [5] listed some of the shortcomings of the systems currently available, such as the limited number allowed in this area and the character strings (50 characters only).

Based on the present rate of growth in using such mobile devices, it is prospective that such devices will soon be used in e-learning platforms like computers. Developing e-learning programs and platforms to adjust to the new stage will be urgently required, in addition to improving portals for these devices and finding useful ways to integrate them into e-learning programs in terms of functionality, design and features [29].

The expansion of social networks and their impact on future social learning is another trend worthy of note. This may be used in e-learning through interactive and collaborative tools given by networks. Social networks such as Facebook, Twitter and others are used by millions of people all over the world and form an ideal place to upload and share learning data; where learning materials uploaded by users may be multimedia files, or text. It can also serve as a portal for e-learning [3].

\section{A. RESEARCH HYPOTHESES}

This study has only one hypothesis, which is:

$\mathrm{H}_{\mathrm{o}}$ : There is no statistically significant difference between total scores before/pre-test and total scores after/posttest in intervention program of writing skills for deaf students.

\section{B. Methodology}

The research design in this research is experimental using a pre-test and post-test to collect data. The study uses an experimental method to examine the improvement of the deaf student writing skills. The experimental research provides insight into the educational practices, creating research to provide details of increased motivation, participation, and other factors that must be considered to succeed. Experimental research is therefore a powerful tool for understanding the writing skills of the hearing-impaired students who face difficulty in their writing skills (Dean \& Voss, 1999). The population of the study will consist of the entire deaf students in intermediate schools in Saudi Arabia. The total population is approximately (8622) student According to the General Administration of Special Education in Saudi Arabia. Therefore, the researcher conducted sampling procedure by choosing random sample the reason is that random sampling eliminates bias by giving everyone an equal chance of selection. The advantages of simple random sampling are the ease of sampling collection and facilitating in mitigating the factors observed in the study [9, 2]. In this study, 240 deaf students who use mobile device in intermediate-school students in Saudi Arabia for the questionnaire and 26 deaf students in Makkah region were selected for the pretest-posttest. The sample will be one-group pretest-posttest design. Analysis of the answers of the questionnaire will be based on the Statistical Package of Social Sciences (SPSS) and Amos.

The researcher used the questionnaire as a tool to collect data for the subject of the study, which is suitable for the study axes. The questionnaire was designed, which included 13 questions, each of which has four measures to answer (Yes, often, rarely, never). This study, divided into three main axes as follows. : The first axis: Investigate the use of deaf students for mobile so that the researcher can see the extent of mobile use among deaf students. The second axis: writing skills of deaf students through which the researcher can know the level of students in mastering these skills. The third axis: the use of mobile communication in writing to help the researcher to know the student attitude towards the use of mobile in improving their writing skills.

The questionnaire was sent to six experts in the Ministry of Education and some universities in the Kingdom of Saudi Arabia to assess whether the elements are compatible with the measures being measured. The experts consisted of lecturers in the field of educational technology, lecturers in the field of educational research, and the supervisor of hearing disabilities in the Department of Education in Jeddah. Their observations and observations were taken into consideration.

\section{RESULTS}

\section{A. DEMOGRAPHIC VARIABLES PROFILE}

Table 1 presents the frequency and percentage of the demographic variables in the research namely: Gender and Age. Number of Male deaf students 146 (59.1\%) is higher than number of Female 101(40.9\%).

TABLE I Frequency ANd PeRCENTAGe of Gender ANd AGe CATEGory

\begin{tabular}{|l|l|l|l|}
\hline \multicolumn{1}{|c|}{ Factor } & Frequency & Percent $(\%)$ & $\begin{array}{c}\text { Cumulative } \\
\%\end{array}$ \\
\hline Gender & \multicolumn{3}{|c|}{ ( Age Category } \\
\hline Male & 146 & 59.1 & 59.1 \\
\hline Female & 101 & 40.9 & 100.0 \\
\hline Total & 247 & 100.0 & 32.0 \\
\hline \multicolumn{4}{|c|}{} \\
\hline $15-25$ & 79 & 32.0 & 74.9 \\
\hline $26-35$ & 106 & 42.9 & 96.4 \\
\hline $36-45$ & 53 & 21.5 & 100.0 \\
\hline $46-55$ & 9 & 3.6 & \\
\hline Total & 247 & 100.0 & \\
\hline
\end{tabular}


As shown in Table 1, the highest Age category is 26-35 with a frequency of 106 (42.9\%), followed by the Age category of 15-25 with a frequency of 79 (32.0\%) and Age category of $36-45$ with a frequency of 53 (21.5\%). The lowest category from Age is category of 46-55 with a frequency of $9(3.6 \%)$.

\section{B. DESCRIPTIVE STATISTICS}

Table 2 shows the descriptive statistics for deaf students before and after intervention program. The number of deaf students in each group was equal (26), and no missing data. Similarly, the Standard Error Mean for group before $(.470)$ is somewhat identical with group after intervention program (.450).

It is observable that Mean's score for pretest is less than Mean's score for posttest with equivalence of Standard Deviation for pretest and posttest $(M=4.65, S D=2.399$ / $M=8.92, S D=2.296)$. In other words, Mean's score for posttest is higher than its pair for pretest, representing the effectiveness of intervention program of writing skills for deaf students.

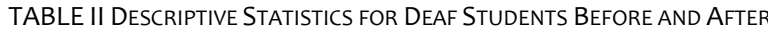
INTERVENTION PROGRAM

\begin{tabular}{|l|l|c|c|c|c|}
\hline \multicolumn{2}{|l|}{} & Mean & N & $\begin{array}{c}\text { Std. } \\
\text { Deviation }\end{array}$ & $\begin{array}{c}\text { Std. Error } \\
\text { Mean }\end{array}$ \\
\hline $\begin{array}{l}\text { Pair } \\
1\end{array}$ & Pretest & 4.65 & 26 & 2.399 & .470 \\
\hline & Posttest & 8.92 & 26 & 2.296 & .450 \\
\hline
\end{tabular}

\section{HYPOTHESIS RESULTS}

The hypothesis result presents the correlations between total scores before / pretest and total scores after/posttest for writing skill program. From Table 3, linear correlation between total scores before / pretest and total scores after / posttest were observed to be statistically significant $(p=0.000)$. Pearson correlation coefficient of 0.714 indicated that the total scores before / pretest and total scores after/posttest were strongly and positively correlated at level of significance $(P)=.000$ as shown in Table 3.

TABLE III Frequency ANd Percentage of Gender ANd AGe CATEGory

\begin{tabular}{|l|l|c|c|c|}
\hline \multicolumn{2}{|l|}{} & N & Correlation & Sig. \\
\hline Pair 1 & Pretest \& Posttest & 26 & .714 & .000 \\
\hline
\end{tabular}

Table 4 displays the parameters for testing the significance of the hypothesis The hypothesis. Mean of difference between total scores before / pretest and total scores after / posttest in intervention program of writing skills was -4.269 with standard deviation of 1.779 and Std. Error Mean of. 349. The mean is obtained from Table 2 (4.65-8.92). Confidence Interval of the Difference was between -4.988 and -3.551 . Degree of freedom was 25 (number of cases 26-1). The parameters of Table 4 are good criteria to take decision about significance of hypotheses of the research.

Null hypothesis stated "there is no statistically significant difference between total scores before /pretest and total scores after/posttest in intervention program of writing skills for deaf students.

Both t-value $>1.964$ and p-value (denoted by Sig. (2-tailed)) <.05 assert the significance of the difference/relationship/hypothesis. Table 3 indicates that $t$-value was 12.237 ( $t>1.964)$ and $P$-value was .000 $(P<.05)$. The significant value of $P$ is less than (0.05), and accordingly, the researcher rejects the null hypothesis and accepts the alternative one which states that: there is statistically significant difference between total scores before/pretest and total scores after/posttest in intervention program of writing skills for deaf students.

TABLEIV RESULT OF HYPOTHESIS

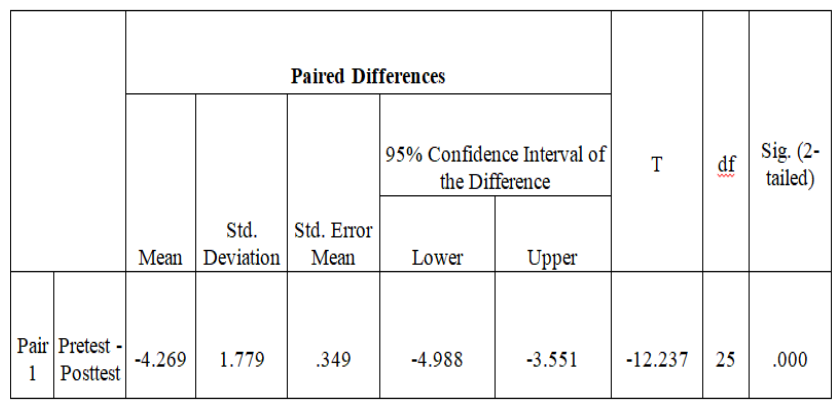

\section{CONCLUSION}

This research examined the effect of students' attitude at $\mathrm{Al}$ Riyadh city between total scores before/pretest and total scores after/posttest in intervention program of writing skills for deaf students. After collecting and analyzing the data using SPSS, regression analysis showed that there is statistically significant difference between total scores before/pretest and total scores after/posttest in intervention program of writing skills for deaf students. This means that the intervention program of writing skills for deaf students is very important to improve their skills.

\section{References}

[1] Abdulghafoor, M. S., Ahmad, A., \& Huang, J. Y. (2015, April) Survey on the use of applications for deaf and hard hearing literacy. In Computer, Communications, and Control Technology (I4CT), 2015 International Conference on Computer, Communication and Control Technology (pp. 242-247). IEEE.

[2] Abdulsalam, A. (2010, December). Assistive educational technology. In Qatar Foundation Annual Research Forum Proceedings (No. 2010, p. CSP4). Bloomsbury Qatar Foundation Journals.

[3] Adkins, S. S. (2008). The US Market for Mobile Learning Products and Services: 2008-2013 Forecast and Analysis. Ambient Insight. 5. Retrieved June 8, 2009 
[4] Agal, S. (2012). Teaching for people with hearing disabilities. Jordan: Dar Almasearah

[5] Al-Khalifa, H. S. (2010). Introducing Arabic Sign Language for Mobile Phones. 12th International Conference on Computers Helping People with Special Needs. Vienna University of Technology, Austria

[6] Al Mulhim, E. (2014). The Barriers to the Use of ICT in Teaching in Saudi Arabia: A Review of Literature. Universal Journal of Educational Research, 2, 487-493.

[7] Antia, S. D., Reed, S., \& Kreimeyer, K. H. (2005). Written language of deaf and hard-of-hearing students in public schools. Journal of Deaf Studies and Deaf Education, 10(3), 244-255.

[8] Anzi, Khalaf (2009). The effect of using cooperative learning strategy in the development of some grammatical skills of students with disabilities acoustically in the first grade secondary in Riyadh, Faculty of Education, Umm Al Qura University, Saudi Arabia.

[9] Asadullah, S., Syed Inayatullah, S., \& Abdul Salam, S. (2016). Research methodologies an Islamic perspective.International Islamic University. Malaysia.

[10] Assaleh, K., Shanableh, T., Fanaswala, M., Amin, F., \& Bajaj, H. (2010). Continuous Arabic sign language recognition in user dependent mode. Journal of Intelligent Learning Systems \& Applications, 2(1), 19-27.

[11] Berndsen, M., \& Luckner, J. (2012). Supporting students who are deaf or hard of hearing in general education classrooms: $A$ Washington State case study. Communication Disorders Quarterly, 33(2), 111-118.

[12] Dorn, L. J., \& Soffos, C. (2001). Scaffolding Young Writers: A Writer's Workshop Approach. Stenhouse Publishers.

[13] Dean, Angela M., Voss, Daniel (1999), Design and Analysis of Experiments, Springer-Verlag New York

[14] Gunning, T. G. (2012). Creating literacy Instruction for All Students. Pearson Higher Education.

[15] Golafshani, N. (2003). Understanding reliability and validity in qualitative research. The Qualitative Report, 8(4), 597-606. Retrieved, fromhttp://www.nova.edu/ssss/QR/QR84/golafshani.pdf

[16] Hamilton, \& Harle. (2012). The Efficacy of Dictionary Use while Reading for Learning New Words.Online Submission

[17] Keating, E. \& Mirus, G. (2003). Examining interaction across language modalities: deaf children and hearing peers at school. Anthropology and Education Quarterly.

[18] Lissi, M. R., Cabrera, I., Raglianti, M., Grau, V., Salinas, M., Grau, V., Acuña, X. (2010). Using Sign Language to teach written language: an analysis of the strategies used by teachers of deaf children in a bilingual context. L1-Educational Studies in Language and Literature, 10(1), 57-69.
[19] Mahmoud, A (2007). Some active learning strategies and realistic calendar effect in the development of some of the written expression skills in first grade secondary pupils, Studies in Curriculum and Altdras- Egypt, GS, pp. 111 -129.

[20] Mayer, C. (2007). What really matters in the early literacy development of deaf children. Journal of Deaf Studies and Deaf Education. doi:10.1093/deafed/enmo20

[21] Mayer, C. (2010). 10 The Demands of Writing and the Deaf Writer. The Oxford Handbook of Deaf Studies, Language, and Education, 2, 144.

[22] Mitchell, R. E., \& Karchmer, M. A. (2011). Demographic and achievement characteristics of deaf and hard-of-hearing students. Oxford Handbook of Deaf Studies, Language, and Education, 1, 18-31.

[23] Paul, P. V. (2009). Language and Deafness. USA: Jones \& Bartlett Learning.

[24] Power, D., Power, M. R., \& Rehling, B., (2007). German deaf people using text communication: Short message service, TTY, relay services, fax, and email. American Annals of the Deaf, 252, 291-301,

[25] Rais, T., \& Manee, O. (2009). Reading Comprehension and written expression among the deaf students enrolled in colleges of Technical and Vocational Training Corporation in Saudi Arabia, An Empirical Study. Technical and Vocational Training Corporation. Arab Academy for special Educational magazine- Riyadh, Saudi Arabia.

[26] Salama, A. H. (2010). Multi-media design and production. Riyadh, Saudi Arabia: Dar Khuraiji for publication and distribution.

[27] Sayed. Howaida S (2011). Proposal to hire some of the online tools model in the development of achievement and the ability of literacy among deaf students, the Arab Society for Educational Technology magazine, a scientific journal periodically Court, Arab Society for Technology Education.

[28] Soudi, A. (2013, November). Assistive technology for improved literacy among the deaf and hard of hearing. In Qatar Foundation Annual Research Conference (No. 2013, pp. ICTP-05).

[29] Venkatesh, V., Morris, M. G., Davis, G. B., \& Davis, F. D. (2003). User acceptance of information technology: Toward a unified view. MIS Quarterly, 27(3), 425-478.

[30] Yousef, M., \& Hamideh, Z. (2013). Mobile Learning for Education: Benefits and Challenges.International Journal of Computational Engineering Research, 3(6), 93. 